\title{
The Foreign Affairs of a State is Based on Its Strength in the International System
}

\author{
Burim Mexhuani PhD \\ European University of Tirana, Tirana, Albania.
}

\begin{abstract}
Neorealists say that a country's Foreign Affairs is based on its power or position as the power that has a state in the international system. Field of International Relations based on international legal policies and norms; It can be defined by different political perspectives and phenomena, depending on certain theories. Theories are the best determinant of defining policies in the International System. For a long time, in the international system have dominated realistic, liberal and radical theories; After the Second World War for the purposes of explaining or defining international policies, other theories, including neo-realism, were listed. As a structured theory versus reality that defined the theory of alignment for defining political theories in the international system. In International Relations there is no central authority or world government, the state and the international environment is in a state of anarchy, which pushes the states to create the conditions to create an environment where they can survive. Special studies of International Relations theory were spurred especially after World War I and World War II. The neorealistic theory itself contains some elements that differ from other theories and that as its base takes the strength or position of power of states in the international system. Responses to the framework of action, the theories are directed as perimeters to solve the problems of the international system. The international relations system may be positioned in other circumstances when a power is not balanced, depending on the different circumstances of politics and politicians.
\end{abstract}

\section{Keywords: International Relation, State, China, Theory, Foreign Affairs}

\section{Introduction}

One of the key questions in international relations and Foreign Affairs is the question of how you examine state behavior. This is the level of analysis problem. Scholars see several levels of analysis through which state behavior can be examined.

System level analysis examines state behavior by looking at the international system. In this level of analysis, the international system is the cause and state behavior is the effect. Characteristics of the International System cause states to behave the way they do. Change in the international system will cause a change in state behavior. The key variable in the international system is the power of a state within the system. Some states are powerful; others are weak. So for example, the cold war had two powerful states. Therefore the central cause of all state behavior in the cold war was the fact that the US and USSR were the two powerful states in a bipolar system. Today, there is unipolar system - one superpower (or hyperpower) -- and that defines the behavior of all other states in the system. (See neo-realism below). So this level of analysis might explain the US intervention in Iraq as a matter of the US, the one, and only powerful state, flexing its muscles to police the world against states that threaten it. The US wants to preserve its dominance and therefore crushes all challengers.

State level analysis examines the Foreign Affairs behavior of states in terms of state characteristics. For example, some scholars say that all democracies behave a certain way; they don't fight with other democracies. Some scholars might look at the different behaviors of weak or strong states; states that live in rough neighborhoods (Germany or France) vs. states that live in more benign surroundings (the US). Some scholars might say that the Foreign Affairs behavior of every state is a cultural characteristic, defined by the historical legacy of the state, the religious or social traditions, or the economic and geographic nature of the state itself (see constructivism below). State level of analysis might explain the US intervention in Iraq as a function of the missionary quality of US foreign policy. The US has always had an idealist streak in its Foreign Affairs (some disagree with this) and sees "bad guys" out there in the international system. The US is compelled by the nature of its political system and its belief that someday all states will be like the US. It has the drive to remake the world 
in its own image. The job of US Foreign Affairs is not done until all states are democratic and all nations have free market economies.

The organizational level analysis examines the way in which organizations within a state function to influence Foreign Affairs behavior. States don't make decisions. Organizations bargain with each other to create a Foreign Affairs that is a compromise between competing organizations. This level of analysis, for example, might look at the lraq war and try to explain it by examining the interests of the US military, the department of defense, the state department, and central intelligence agency. How did these organizations create US Foreign Affairs would be the key question at this level of analysis? The individual level analysis focuses on people. People make decisions within nation states and therefore people make foreign policy. Scholars might look at the roles of different leaders. This level of analysis might explain World War II by examining the role of Hitler. It might look at the end of the cold war by studying Gorbachev. It might suggest that the economic reforms in China are a result of the transition from Mao Zedong's leadership to Deng Xiaoping's rule. This level of analysis also includes cognitive theories --- theories that explain Foreign Affairs by looking at the way leaders perceive the world. Larson's book is an example of this. This is a focus on perception, misperception, and communication. The individual level analysis might ask questions such as these: Are there aspects of George W. Bush's character and belief systems that have defined the US response to the 9/11 attacks? Would AI Gore or John Kerry have behaved any differently in a similar situation? How do Bush and his senior decision makers perceive the world and their role in it?

One of the theorists who supported the neo-realistic theory was Kenneth Waltz, who transformed the realistic theory into "structural realism". According to Waltz, this theory is an intellectual construct, we select the facts and interpret them. Neorealists use a more scientific system that can explain events by raising norms or laws in the relationships of the international political system. Neo-realists based on power distribution as well as systemic factors in international politics, depending on behavior in this system, also follow gains and losses depending on their behavior in the system. Neo-realistic theory of particular importance emphasizes the balance of power or its balancing. While Waltz is one of those who offered his own ideas for neo-realistic theory, other authors of neorealism are also considered Stephen Krasner and Robert Gilpin, who arguably argue about globalization. They stressed that the role of the state should be turned into the world where transnational economic gambling does not minimize the role of the state. International standards to adapt their behavior rely on interests that states try to create through influences or other actors in the system, but not by damaging the system and other actors in the system (Keohane, 1994). States that can be distinguished for a support of neo-realistic theory are China, Russia, the EU in relation to the system or Germany and Japan, etc., which want to descend power from the unipolar system into a multipolar system. As a concrete example, we have taken China's role in the system, based on its potential as a very important factor especially after the rapid economic growth and after the North Korean crisis on nuclear power issues.

\section{Political debates}

Neo-liberalism is an offshoot of liberalism. It is a system level version of liberalism and focuses on the way in which institutions can influence the behavior of states by spreading values or creating rule-based behavior. Neo-liberals might focus on the role of the United Nations or World Trade Organization in shaping the Foreign Affairs behavior of states. Neoliberals might look at the cold war and suggest ways fix the UN to make it more effective. The neo-realistic theory states that states are rational actors that adopt their behavior, based on the structured boundaries of the international political system. Neorealists point out that "the state as powerful as possible, other actors will incorporate into the system and try to influence different ways on different actors (Deutch, 1994).

So China is a powerful country and tries to create influential policies on states and other actors for various problems. I can say that China has played an important role, especially in the east, seeing the economic development and other potentials it possesses.

Demands by neo-realists to succeed a state in the international system are tied to three issues:

Configuration mode (depending, what is the role of policy in that region)

Created functional bases

States perform the same functions with different abilities (depending on the role of creating relationships with different actors). 
Such a condition enables China to have a sustainability to be imposed on the international system, considering it is part of the UN Security Council. Neorealists said that the power position of a state is determined by the international system and the distribution of political, military, economic power in the system. China as an influential political power to be one of the main actors especially of the birth would rise in all the political, economic, and security strings. Searching states for strength (power) with the power to compete or for strategic advantage rose to exploitation ways to influence their policies. From this, we can say that "Chinese reforms" though not planned would be realized when the economic, political and social climate enables or requires reforms (Goldstein, 2011).

- In recent years, China has achieved a high economic growth, with a high sense of national cohesion with a stronger and stronger army. The pursuit of their national interest will be in relation to the international environment by accepting the rules of political culture as well as their role in international organs. The international system based on the changes of recent years is increasingly approaching a function of state socialization by taking into account the differences between the great and the small powers. However, this socialization shakes states toward the security dilemma that creates supportive circumstances, depending on their role for certain policies. The international society needs to develop cognitive and communicative forms of action among the actors to create a sequence, but the nature of the forces has led the international system to be anarchic. With this, it can be said that China is one of the serious actors in relation to the international environment. "During the Cold War, China made important strategic steps in the equilibrium role between the two world superpowers (Kissinger, 210).

- The neo-realistic theory defines that Foreign Affairs is based on moments of crisis and the way they are used, which is preferable to autonomy than influential spheres. On this basis, China has successfully managed North Korea's crisis, is one of the most important aorta to achieve a lasting solution. A confrontation policy between China (in the case of North Korea's support) and America would jeopardize American isolation in Asia. No Asian country would support America in any conflict with China. However, neither China was willing to interfere in conflicting relations with America. The trade deal pushed for further advancement of relations between China and other states. "The issue of security in neo-liberal politics devotes particular importance to autonomy and other actors, but there is no pressure on this issue" (Goldstein, International Relations (10th Edition), 2011).

- $\quad$ Small and powerless states need to make deals or things similar to powerful states. Connections between China and other states in the eastern region, especially with Japan and Islamic countries, would be a challenge for a global order and security. Neorealism theory considers military strength to be very important for the imposition of international policies, which may have reflections across the international system. Thus, a balance of power between the actors, especially the Americas, the EU and the countries of origin, needs to be balanced. "The international agreement on power management should legitimize the importance that favors the mighty" ( Scott Burchill (Author), Andrew Linklater (Author), Richard Devetak (Author), Jack Donnelly (Author), Terry Nardin (Author), Matthew Paterson (Author), Christian Reus-Smit (Author), Jacqui True , 2009).

- China as an important factor in the multi-level maturity region of security, economy, global politics, etc., should be seen as a country that can have the support of creating peoples of peace. According to Neo-realist ideas, the most unsafe system is the unipolar system, while the best would be bipolar, while multipolar systems are less stable than bipolar systems and content is difficult to achieve because there can always be misunderstandings and misstatements of force and motive.

- China's foreign policy, according to political engagement, seems to be focused on some issues where it can be emphasized as the most primary:

- global cooperation in the field of security

- peaceful settlement of conflicts and respect for state sovereignty

- $\quad$ economic growth through cooperation and trade regional cooperation

- acceptance of the rules of diplomatic culture, etc. 


\section{Conclusions}

The role of international theories is undoubtedly one of the closest opportunities to define the policy of a political actor. However, this depends on the factors that may interfere in certain cases. The neo-realistic theory emerged as an alternative which strives to articulate striking principles by selecting and interpreting them. International Society to raise mutual interests and values, rules and institutions seeking solutions or as called "Problem Solving Theory". Since all things are transitory, then this opportunity can be articulated and things will be defined towards a globalist society.

International affairs are trying to find an ideal peace and security for the good of humanity, in the state of anarchy of the international system is hard to think. However, policies need to be found to build a safer international society. Theories of international relations are pushing to manage and solve various controversial circumstances, always in the role of protecting human values. Neorealist Theory supports a certain number of evaluations related to particular political issues.

As a matter of appreciation for the role of neo-realistic theory, states should be able to create self-confidence, create the capacity to create an obligatory order that states are obliged to respect, create opportunities to create alliances by Distribute power, move to the state of power operationalism, etc. Especially for states that must survive anarchy should create policies that respect sovereignty and create the conditions to survive.

The synthesis of Neorealism and Neoliberalism is warranted: a systemic theory using the former to analyze at the level of structure, the latter more often at the level of the process.

\section{References}

[1] Scott Burchill (Author), Andrew Linklater (Author), Richard Devetak (Author), Jack Donnelly (Author), Terry Nardin (Author), Matthew Paterson (Author), Christian Reus-Smit (Author), Jacqui True. (2009). Theories of International Relations. Palgrave Macmillan; Fourth Edition edition.

[2] Deutch, K. (1994). The Analysis of International Relations. Tirana: Toena.

[3] Goldstein, J. S. (2011). International Relations (10th Edition). London: Pearson.

[4] Goldstein, J. S. (2011). International Relations (10th Edition). New York: Pearson.

[5] Goldstein, J. S. (2011). International Relations (10th Edition). New York: Pearson.

[6] Keohane, R. O. (1994). Neorealism and its Critics. The MIT Press.

[7] Kissinger, H. A. (210). Diplomacy. New York: Simon \& Schuster Paperbacks. 